\section{DIACRONIE}

\section{Diacronie}

Studi di Storia Contemporanea

$\mathrm{N}^{\circ} 34,2$ | 2018

Scuola e società in Italia e Spagna tra Ottocento e Novecento

\title{
Ferdinando Gabriel Romero, El imperialismo y el agro argentino. Historia reciente del capital extranjero en el complejo agroindustrial pampeano
}

Hugo Ariel Rossi

\section{OpenEdition}

Journals

Edición electrónica

URL: http://journals.openedition.org/diacronie/7819

DOI: 10.4000/diacronie.7819

ISSN: 2038-0925

Editor

Association culturelle Diacronie

Referencia electrónica

Hugo Ariel Rossi, «Ferdinando Gabriel Romero, El imperialismo y el agro argentino. Historia reciente del capital extranjero en el complejo agroindustrial pampeano », Diacronie [En línea], №34, 2 | 2018, Puesto en línea el 29 junio 2018, consultado el 24 septiembre 2020. URL : http://journals.openedition.org/ diacronie/7819; DOI : https://doi.org/10.4000/diacronie.7819 


\section{Diacronie}

Studi di Storia Contemporanea

34, $2 / 2018$

Scuola e società in Italia e Spagna tra Ottocento e Novecento

\section{PANORAMICA: Argentina 2017}

\section{Hugo Ariel ROSSI, Ariel Ignacio SLAVUTSKI}

Per citare questo articolo:

ROSSI, Hugo Ariel, SLAVUTSKI, Ariel Ignacio, «PANORAMICA: Argentina 2017», Diacronie. Studi di Storia Contemporanea : Scuola e società in Italia e Spagna tra Ottocento e Novecento, 34, 2/2018, 29/06/2018,

URL: < http://www.studistorici.com/2018/06/29/argentina_numero_34/ >

Diacronie Studi di Storia Contemporanea $\rightarrow$ http://www.diacronie.it Rivista storica online. Uscita trimestrale.

redazione.diacronie@hotmail.it

Comitato di direzione: Naor Ben-Yehoyada - João Fábio Bertonha - Christopher Denis-Delacour - Maximiliano Fuentes Codera Anders Granås Kjøstvedt - John Paul Newman - Deborah Paci - Niccolò Pianciola - Spyridon Ploumidis - Wilko Graf Von Hardenberg

Comitato di redazione: Jacopo Bassi - Luca Bufarale - Gianluca Canè - Luca G. Manenti - Fausto Pietrancosta - Alessandro Salvador - Matteo Tomasoni - Luca Zuccolo Creative Commons 3.0. Possono essere riprodotti e modificati a patto di indicare eventuali modifiche dei contenuti, di riconoscere la paternità dell'opera e di condividerla allo stesso modo. La citazione di estratti è comunque sempre autorizzata, nei limiti previsti dalla legge. 


\section{4/ PANORAMICA: Argentina 2017}

Hugo Ariel ROSSI, Ariel Ignacio SLAVUTSKI

\section{ROMERO, Ferdinando Gabriel, El imperialismo y el agro argentino.}

\section{Historia reciente del capital extranjero en el complejo agroindustrial} pampeano, Buenos Aires, Ediciones CICCUS, 2016, 512 pp.

Hugo Ariel ROSSI

Sobre el rol del imperialismo en la economía argentina se ha escrito mucho. No obstante, este libro propone una mirada innovadora sobre el mismo, ya que describe y analiza en detalle el proceso de extranjerización y desnacionalización del núcleo productivo más importante del país como es el sector agrario pampeano.

Las conclusiones generales de los capítulos podrían resumirse en que todos ellos muestran el alto grado de extranjerización y desnacionalización del núcleo productivo más importante de la economía del país como es el complejo agroindustrial pampeano. De esta manera la dependencia del capital extranjero por parte de Argentina, implica que los ingresos que el país obtiene por la venta de su producción agraria se transformen al mismo tiempo en un importante drenaje de divisas para la compra de los insumos tecnológicos necesario para el mantenimiento de los niveles productivos.

A lo largo de este trabajo podemos observar que las grandes transformaciones del complejo agroindustrial pampeano, son el resultado de los procesos históricos de cambios en la formación económica social argentina a lo largo de todo el siglo XX. Es precisamente en este punto donde se encuentra el principal aporte del libro a la compresión del fenómeno del imperialismo: el autor nos muestra con toda claridad el nexo histórico que une a las clases dominantes argentinas con el capital extranjero. De esta manera los procesos de extranjerización y desnacionalización ya no son entendidos como una mera consecuencia de fenómenos externos a la economía nacional, sino que por el contrario, a lo largo del tiempo y en cada coyuntura histórica del país, existió una clara simbiosis entre grupos de poder locales y empresas foráneas. 


\section{BASUALDO, Eduardo, SANTARCÁNGELO, Juan, WAINER, Andrés, RUSSO, Cintia, PERRONE, Guido, El Banco de la Nación} Argentina y la dictadura. el impacto de las transformaciones económicas y financieras en la política crediticia (1976-1983), Buenos Aires, Siglo

\section{Veintiuno Editores, 2016, 320 pp.}

Hugo Ariel ROSSI

El Golpe de Estado del 24 de marzo de 1976 instaló en la República Argentina una dictadura militar que se prolongaría hasta el año 1983. En ese lapso de 7 años la Junta Militar llevó a delante un plan sistemático de represión social con el objetivo de disciplinar al conjunto de la sociedad argentina y al movimiento obrero en particular.

Sin embargo este avasallamiento de los derechos civiles no se comprende en su totalidad si no se presta atención al plan económico llevado adelante por las Fuerzas Armadas Argentinas, el cual consistió en un proceso de valorización financiera en base a un fuerte financiamiento externo mediante toma deuda. La consecuencia directa de este nuevo patrón de acumulación fue la fuga de divisas al exterior y una gran desindustrialización del aparato productivo argentino.

Dentro de este esquema macroeconómico de neto corte neoliberal, el Banco Nación jugó un rol esencial en la política monetaria del plan económico de los militares argentinos. Es por ello que el libro "El Banco de la Nación Argentina y la Dictadura" viene a constituirse en una pieza importante para la comprensión de como fue la actuación de la principal entidad bancaria nacional en aquellos años. La cual consistió en oficiar de agente intermediario, endeudamiento en el exterior mediante, entre las entidades financieras extranjeras y las locales. Y al mismo tiempo por medio de una reestructuración organizativa del Banco -que incluyo además de despidos, la desaparición de personal- muchos representantes de estas fracciones de lo más concentrado del capital local pasaron a ocupar puestos claves en el directorio, participando de esta manera en el diseño de las política económicas del periodo.

\section{RAPOPORT, Mario, Historia oral de la política exterior argentina.} (1966-2016), Buenos Aires, Editorial Octubre, 2016, 912 pp.

Hugo Ariel ROSSI

El análisis de la política exterior de la Argentina no solo es importante como campo de estudio en sí mismo, sino que resulta necesario para lograr una mayor comprensión de los cambios y 
transformaciones que atravesó el país a lo largo de su historia. Es en este sentido que el libro "Historia Oral de la Política Exterior Argentina", constituye un valioso aporte al abordaje de la historia contemporánea argentina. Con la particularidad que en él encontramos dos aspectos interesante, por un lado el análisis particular de cada uno de los ejes más destacables de la últimas décadas en materia de las relaciones internacionales del país, y por otro lado - y esto es lo que resulta más interesante aún - una serie de entrevistas realizadas a personajes claves en la política exterior. Lo que también constituye al trabajo en una fuente documental de gran importancia.

El recorte temporal va desde el año 1966 - es decir con el Golpe de Estado conocido como "Revolución Argentina" - hasta los primeros meses de 2016 inclusive. La selección de este periodo es interesante debido a que el fin del segundo gobierno de Juan Domingo Perón en el año 1955 inauguró en la República Argentina toda una etapa de profundas transformaciones, la cuales se expresaron: en lo político, con los continuos Golpes de Estados llevados adelantes por las Fuerzas Armadas, en lo social por la agudización de los conflictos entre un movimiento obrero organizado y las diversas entidades patronales, y en lo económico por los ciclos de crecimiento y estancamiento de la economía del país.

Podría decirse que el libro se encuentra divido en dos grandes partes. La primera de ellas, en donde se abordan cuestiones claves de la política internacional argentina, consta de dos grandes apartados. El primero dedicado más a una descripción de los principales ejes que articulan la política exterior del país, y el segundo enfocado más a un análisis de las instituciones que dan forma a la política exterior del estado argentino. Finalmente en la segunda gran parte del libro encontramos las entrevistas realizadas a los protagonistas de los temas abordados en los capítulos anteriores. 


\section{REATI, Fernando, CANNAVACCIUOLO, Margherita (eds.), De la}

Cercanía emocional a la distancia histórica. (Re) presentaciones del terrorismo de Estado, 40 años después, Buenos Aires. Prometeo libros, 2016, 333 pp.

Ariel Ignacio SLAVUTSKY

Perseguir lo inasible, presentificar o en los términos utilizados por los autores representar el terrorismo de Estado es una tarea que ha obsesionado por cuarenta y un años a militantes por los derechos humanos, familiares, artistas y científicos sociales.

Esta obra intenta compilar en catorce artículos las distintas formas en la que estos agentes han intentado hacer presentes las atrocidades llevadas a cabo por el último gobierno de facto. Las distintas formas de intervención artística revelando lo político en cada una de estas acciones.

El espacio juega aquí un rol fundamental, el río, la calle, las banderas en las manifestaciones, las marcas en los centros clandestinos de detención, son intentos de hacer público aquello que debía permanecer soterrado, escondido a la vida ciudadana. Haciendo de cada intervención un espacio para hacer memoria.

De esta manera, el título del libro, de la cercanía emocional a la distancia histórica, debiera estructurarse como pregunta y no como afirmación, ya que, a pesar de la distancia temporal la memoria sigue siendo un ejercicio cotidiano y un remedio para la reiteración de prácticas políticas negacionistas.

\section{FEIERSTEIN, Daniel, Introducción a los Estudios sobre Genocidio,} Buenos Aires, Fondo de Cultura Económica, 2016, 475 pp.

Ariel Ignacio SLAVUTSKY

En este esfuerzo de síntesis, Feierstein, pone en juego toda su experiencia en el área de los estudios sobre genocidio con la finalidad de generar un libro accesible para todo público sin por ello dejar de lado la complejidad.

El libro se estructura dos partes: una introducción teórico-conceptual, donde el autor demuestra toda su experticia en el tema recuperando su preocupación por la despolitización inicial del concepto de genocidio desarrollado por la Organización de Naciones Unidas en 1948 y su repolitización, llevada a cabo a partir de la crítica de los científicos sociales; en la segunda parte, reseña doce casos de genocidios, en un esfuerzo por dar cuenta de las distintas formas de la puesta en práctica de los aparatos genocidas, donde se vuelve evidente su interpretación en torno 
a la amplitud del concepto de genocidio y la utilización del mismo, dentro del proyecto moderno de tanto para la expansión del imperialismo, como para la constitución de los estados modernos.

De esta manera, la obra se presenta como una herramienta pedagógica útil que permite no solo introducirnos a una temática específica sino también empujarnos a repensar las prácticas naturalizadas de la modernidad.

\section{BUCH, Esteban, Musica, dictadura, resistencia. La orquesta de París en} Buenos Aires, Buenos Aires, Fondo de Cultura Económica, 2016, 301 pp.

Ariel Ignacio SLAVUTSKY

El libro propone responder a una pregunta tan antigua como difícil ¿Qué relación existe entre el arte y la política? A partir de allí es posible dividir la obra en dos partes.

En la primera donde recorre los periplos que posibilitaron la visita de la orquesta de París a Buenos Aires. Aquí detalla puntillosamente los pasos de la orquesta y las acciones de los músicos franceses que llevarían a un revuelo diplomático y periodístico reconstruido a partir de una gran cantidad y variedad de fuentes documentales. En su segundo capítulo, da cuenta de la música presentada por la orquesta y su director el judeo-israeli-argentino Daniel Baremboing, haciendo un análisis musicológico de la obra de Mahler.

En la segunda, realiza un análisis que podría calificarse de autobiográfico del rock nacional y de otros compositores clásicos contemporáneos, tales como Kagel y Kusnir. Aquí la pregunta inicial se transforma en respuesta, el arte, y, la música en particular tiene una relación intrínseca con los momentos políticos.

Como en una sinfonía, las últimas páginas ocultan un gran final, allí se revela la historia de una investigación híper subjetiva donde muestra que su hipótesis inicial se relaciona con la construcción de su propia historia/memoria transformando lo anterior en un experimento metodológico original. 


\section{LOS AUTORES / GLI AUTORI}

Hugo Ariel ROSSI ICSOH-CONICET - Universidad Nacional de Salta.

URL: < http://www.studistorici.com/progett/autori/\#Rossi >

Ariel Ignacio SLAVUTSKI Universidad Nacional de Jujuy - Universidad Nacional de Tucumán.

URL: $<$ http://www.studistorici.com/progett/autori/\#Slavutski > 